\title{
Approximation of the index for assessing ship sea-keeping performance on the basis of ship design parameters
}

\author{
Tomasz Cepowski \\ Szczecin Maritime University
}

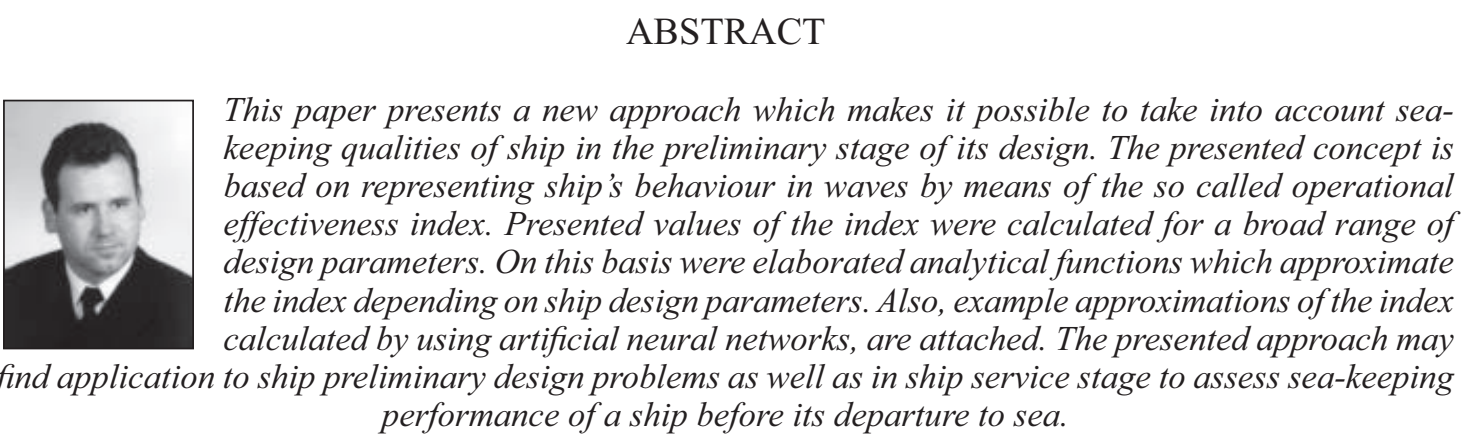

Keywords : sea-keeping qualities, sea-keeping performance index, approximation, ship design parameters, artificial neural networks, rolling, slamming, green-water shipping

\section{INTRODUCTION}

In ship design process an optimum solution which satisfies assumed economical criteria and technical limitations, is searched for. The technical limitations contain a.o. performance of ship in rough seas, the called sea-keeping qualities. However in the preliminary design stage to take into account the whole range of ship sea-keeping qualities is very difficult and rather inaccurate when using current calculation methods. It results from a few problems the most important of them are the following :

$\checkmark$ in the preliminary design stage values of the parameters which significantly influence sea-keeping performance of designed ship are not yet known (they result from ship hull form and mass distribution which are unknown in that stage of designing)

$\checkmark$ simple accurate relationships between design parameters and sea-keeping qualities of ship are unknown

$\checkmark$ in the preliminary design stage, assessment of sea-keeping performance of ship is of a descriptive character, left at designer's discretion and hence imprecise as usual.

In the papers $[6,7]$ was proposed a method of approximation of selected sea-keeping qualities based on ship design parameters and represented by means of amplitude-phase characteristics of ship in regular waves.

On the basis of such approximations it is possible to determine statistical quantities of sea-keeping qualities of ship in rough waves and the operational effectiveness index (acc. [2, 5]) which enables to assess quantitatively sea-keeping performance of a given designed ship. The operational effectiveness index $\mathbf{E}_{\mathbf{T}}$ usually expresses probability of the event that ship response in given wave conditions will not exceed an assumed level. Hence the index $\mathbf{E}_{\mathbf{T}}$ takes values from the interval of 0 to 1 . The higher the index value the better predicted sea-keeping performance. In [8] is presented an example of application of the above mentioned index (and of the approximation acc. $[6,7])$ to selecting optimum design of ship regarding its sea-keeping performance.

The approximations presented in $[6,7]$ make it possible to simply and accurately determine transfer functions of selected sea-keeping qualities. However, the assessing of the sea-keeping qualities on the basis of the operational effectiveness index is associated with the necessity of calculation of their statistical values for ship in irregular waves and probability of occurrence of the wave parameters for which ship's motions exceed an assumed level. The general algorithm of calculation procedure of the index $\mathbf{E}_{\mathbf{T}}$, based on the transfer functions of sea-keeping qualities is presented in Fig.1. The using of the above mentioned algorithm for calculation of the operational effectiveness index is associated with necessity of carrying out many iterations hence the approach can not be applied to multi- criterion optimization methods as the target function as its form is then too much complex. Moreover, to calculate $\mathbf{E}_{\mathbf{T}}$ index value, data on statistical distributions of wave parameters in a given sea area or shipping route should be known, that excludes the method from application to fast assessing a given ship design variant. 


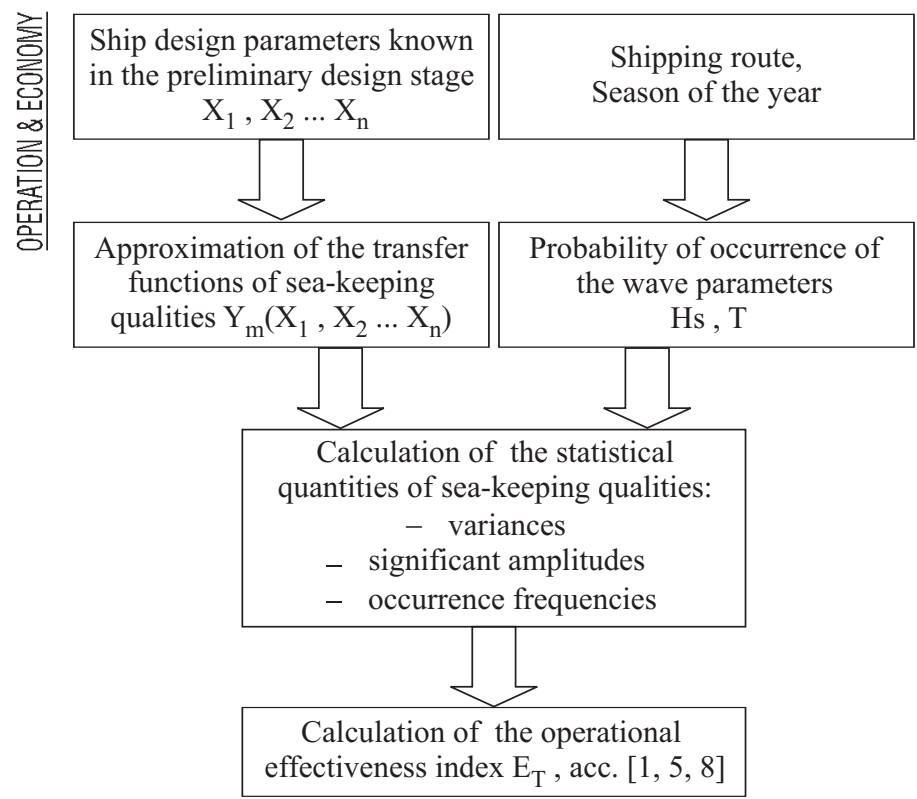

Fig. 1. Schematic diagram of calculation of the operational effectiveness index of sea-keeping qualities, $\boldsymbol{E}_{\boldsymbol{T}}$. Notation : $\boldsymbol{X}_{\mathbf{1}}, \boldsymbol{X}_{\mathbf{2}} \ldots \boldsymbol{X}_{\boldsymbol{n}}-$ ship design parameters, $\boldsymbol{H} \boldsymbol{s}$ - significant wave height, $\boldsymbol{T}$-characteristic wave period, $\boldsymbol{Y}_{\boldsymbol{m}}$ - transfer function of sea-keeping qualities.

\section{CONCEPT}

For the above mentioned reasons in the investigations in question another concept of determining the index $\mathbf{E}_{\mathbf{T}}$ was taken into consideration. To simplify the method described in Fig.1, the approximation of transfer functions of sea-keeping qualities was replaced by the approximation of the index $\mathbf{E}_{\mathbf{T}}$ depending on the ship design parameters $\mathbf{X}_{1}, \mathbf{X}_{\mathbf{2}} \ldots \mathbf{X}_{\mathbf{n}}$ on a given shipping route. The schematic diagram of the concept is presented in Fig.2.

Ship design parameters known in the preliminary design stage $\mathrm{X}_{1}, \mathrm{X}_{2} \ldots \mathrm{X}_{\mathrm{n}}$

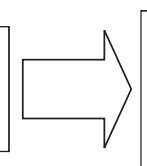

Approximation of the operational effectiveness index $\mathrm{E}_{\mathrm{T}}=\mathrm{f}\left(\mathrm{X}_{1}, \mathrm{X}_{2} \ldots \mathrm{X}_{\mathrm{n}}\right)$

Fig. 2. Schematic diagram of approximation of the sea-keeping qualities index $\boldsymbol{E}_{\boldsymbol{T}}$ on a given shipping route, where : $\boldsymbol{X}_{1}, \boldsymbol{X}_{2} \ldots \boldsymbol{X}_{n}-$ ship design parameters, $\boldsymbol{f}$-searched for approximation function

In such case the effectiveness index $\mathbf{E}_{\mathbf{T}}$ on a given shipping route can be approximated in accordance with the formula (1):

$$
\mathrm{E}_{\mathrm{T}}=\mathrm{f}\left(\mathrm{X}_{1}, \mathrm{X}_{2} \ldots \mathrm{X}_{\mathrm{n}}\right)
$$$$
\text { where : }
$$

$\mathrm{X}_{1}, \mathrm{X}_{2} \ldots \mathrm{X}_{\mathrm{n}}-$ ship design parameters

$\mathrm{f}$ - searched for approximation function.

On the basis of the assumed concept the approximation function $\mathbf{f}$ may concern all selected sea-keeping qualities or only a given one (e.g. rolling or slamming). Values of the index $\mathbf{E}_{\mathbf{T}}$, approximated with the use of the function $\mathbf{f}$, can be related to:

* a given shipping route or region of operation

* a given season or time interval

* a selected type of ships or their group

* an assumed load condition (ballast, full load)

* assumed criterion values of sea-keeping qualities.

The approximation function $\mathbf{f}$ can be determined on the basis of the set of model values of the ship design parameters
$\mathbf{X}_{1}, \mathbf{X}_{2} \ldots \mathbf{X}_{\mathbf{n}}$ and values of the effectiveness index $\mathbf{E}_{\mathrm{T}}$ calculated by using exact methods. The above mentioned approximations can be elaborated by using statistical methods. An example of application of the artificial neural networks to determine the approximation function $\mathbf{f}$ is presented below.

\section{Application of the artificial neural networks to approximate the operational effectiveness index $E_{T}$}

The function for approximating the ship operational effectiveness index $\mathbf{E}_{\mathbf{T}}$ can be determined according to the formula :

$$
\underset{\text { where : }}{\mathrm{X}} \stackrel{\mathrm{f}}{\longrightarrow} \mathrm{Y}
$$

$\mathrm{X}$ - set of assumed ship design parameters

$\mathrm{Y}$ - set of values of the ship operational effectiveness index $\mathbf{E}_{\mathbf{T}}$ calculated by means of exact methods

$\mathrm{f} \quad-$ searched for analytical function in the form of artificial neural network, intended for the approximating of the index $\mathbf{E}_{\mathbf{T}}$.

It was preliminarily assumed that the investigations in question will concern approximation of the sea-keeping qualities which have the most detrimental influence on ship's safety, to which - in accordance with $[2,5]$ - the following ones belong : rolling, slamming, green water shipping onto the deck, propeller emerging, vertical accelerations at bow and bridg, and pitching. And, successive investigations showed that for the considered series of ships in assumed wave conditions vertical accelerations and pitching impair ship's safety to a small extent only. Hence only the values of the operational effectiveness indices which concern the following qualities, were taken into account as the elements of the set $\mathbf{Y}$ in the equation (2) :

$$
\begin{aligned}
+ & \operatorname{rolling}-\left(\mathrm{E}_{\text {Troll }}\right) \\
+ & \text { slamming }-\left(\mathrm{E}_{\text {Tslam }}\right) \\
+ & \text { green water shipping }-\left(\mathrm{E}_{\text {Tgreen }}\right) \\
+ & \text { propeller emerging }-\left(\mathrm{E}_{\text {Tprop }}\right) \\
+ & \text { all the above specified sea-keeping } \\
& \text { qualities in total }-\left(\mathrm{E}_{\mathrm{T}}\right) .
\end{aligned}
$$

And, as the elements of the set $\mathbf{X}$ in the equation (2) the ship design parameters which significantly influence the above mentioned sea-keeping qualities, were taken into account. In compliance with the literature sources $[1,3,5]$ the following ship's parameters were assumed :

$$
\begin{aligned}
& \text { A }- \text { length } \\
& \text { ^ } \mathrm{B}-\text { breadth } \\
& \text { ^ } \mathrm{Cb}-\text { block coefficient of immersed } \\
& \text { } \quad \text { part of ship hull } \\
& \text { ^ } \mathrm{GM}_{0}-\text { initial transverse metacentric height } \\
& \text { ^ } \mathrm{T}-\text { draught. }
\end{aligned}
$$

The process of searching for the best network consisted of the following steps :

$>$ determination of the best network structure by using genetic algorithms

$>$ teaching the network

$>$ testing the network

$>$ assessing approximation accuracy of the network on the basis of test data.

For teaching the neural networks at most $50 \%$ of all the data was utilized not to result in over-teaching the networks. 
For the assessing of approximation accuracy errors in teaching and testing, which can be determined from Eq. (3), were used :

$$
\mathrm{R} M S=\sqrt{\frac{\left(\mathrm{E}_{\mathrm{Tw}}-\mathrm{E}_{\mathrm{T}}\right)^{2}}{\mathrm{n}}}
$$

where :

RMS - value of error

$\mathrm{E}_{\mathrm{Tw}}-$ model (reference) values used in teaching or testing the neural network

$\mathrm{E}_{\mathrm{T}} \quad$ - values calculated with the use of the neural network

n $\quad-$ number of records.

\section{Model values}

As model values the operational effectiveness indices calculated for the North Atlantic in winter were assumed. Values of the indices were calculated for the series of container carriers having the design parameters specified in Tab.1.

Their sea-keeping qualities were calculated by using exact numerical methods with the help of GRIM ${ }^{1}$ software. In Fig. $3-5$ are presented tests of accuracy of the GRIM software as compared with the results obtained by recognized scientific centres (measurements performed in Wageningen model basin, calculations by Delft calculations by the WARES software, Ship Design and Research Centre, Gdańsk). The presented comparison shows very high accuracy and conformity of the calculations performed with the help of GRIM software.

Values of the operational effectiveness indices were calculated in accordance with the algorithm presented in Fig.1 complying with $[2,5,8]$. Criterion quantities for sea-keeping qualities were assumed according to [2]. Calculations of secondary effects of ship oscillation motions were performed for the points indicated in Fig. 6.

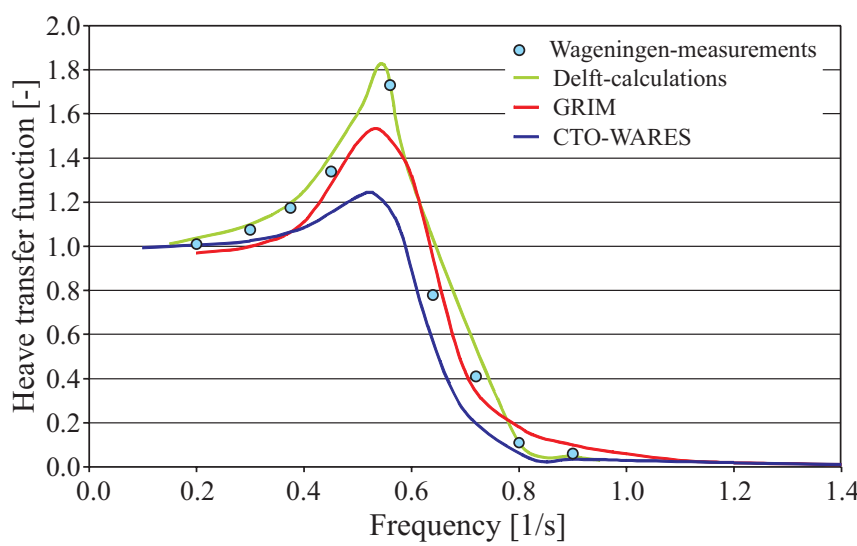

Fig. 3. Comparison of heave transfer functions: $\beta_{w}=90^{\circ}, V=0 \mathrm{kn}$; $200000 \mathrm{dwt}$ tanker of the length $L=310 \mathrm{~m}$, breadth $B=47.17 \mathrm{~m}$, draught $T=18.9 \mathrm{~m} \mathrm{[3]}$

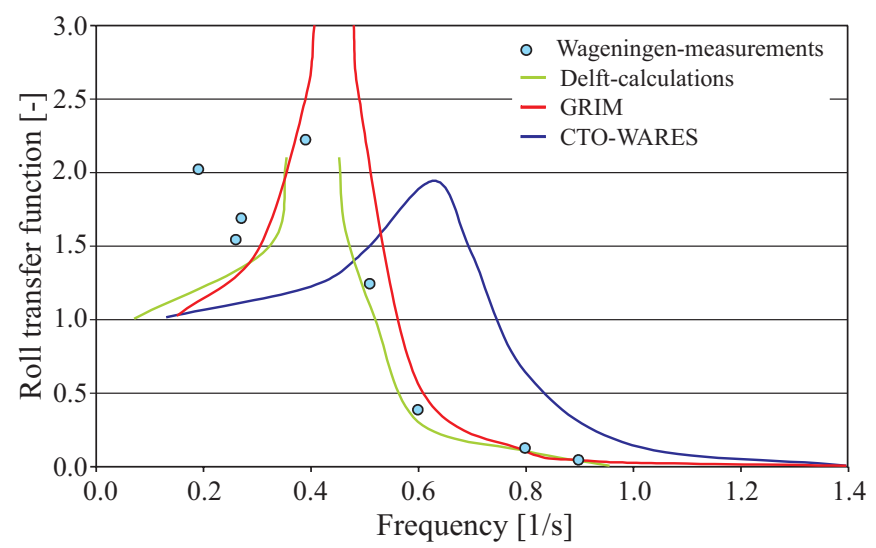

Fig. 4. Comparison of roll transfer functions : $\beta_{w}=90^{\circ}, \mathrm{V}=0 \mathrm{kn}$ 200000 dwt tanker of the length $L=310 \mathrm{~m}$, breadth $B=47.17 \mathrm{~m}$, draught $T=18.9 \mathrm{~m}[3]$

Tab. 1. Model data set :

* the ship design parameters : L-length, B-breadth, $\boldsymbol{C b}$-block coefficient of immersed part of hull, $\boldsymbol{G M}_{0}$ - initial transverse metacentric height, $\boldsymbol{T}$-draught

* the operational effectiveness indices : $\boldsymbol{E}_{\boldsymbol{T}}$-for all sea-keeping qualities, $\boldsymbol{E}_{\text {Troll }}-$ for rolling, $\boldsymbol{E}_{\boldsymbol{T} \text { slam }}-$ for slamming, $\boldsymbol{E}_{\text {Tprop. }}$ - for propeller emerging, $\boldsymbol{E}_{\text {Tgreen }}$ - for green water shipping onto the deck.

\begin{tabular}{|c|c|c|c|c|c|c|c|c|c|c|}
\hline Variant & $\mathbf{L}[\mathbf{m}]$ & $\mathbf{B}[\mathbf{m}]$ & $\mathbf{C b}[-]$ & $\mathbf{G M}_{\mathbf{0}}[\mathbf{m}]$ & $\mathbf{T}[\mathbf{m}]$ & $\mathbf{E}_{\mathbf{T}}$ & $\mathbf{E}_{\text {Troll }}$ & $\mathbf{E}_{\text {Tslam }}$ & $\mathbf{E}_{\text {Tprop. }}$ & $\mathbf{E}_{\text {Tgreen }}$ \\
\hline 1 & 144.6 & 24.1 & 0.67 & 2 & 8.6 & 0.87 & 0.98 & 0.89 & 0.87 & 0.77 \\
\hline 2 & 152.8 & 23.5 & 0.71 & 1.85 & 7.8 & 0.85 & 0.89 & 0.89 & 0.85 & 0.73 \\
\hline 3 & 161 & 23 & 0.75 & 2.41 & 7.2 & 0.81 & 0.88 & 0.88 & 0.82 & 0.7 \\
\hline 4 & 170.3 & 22.7 & 0.78 & 2.92 & 6.7 & 0.77 & 0.94 & 0.87 & 0.8 & 0.67 \\
\hline 5 & 184.2 & 30.7 & 0.78 & 3 & 10.2 & 0.94 & 0.88 & 0.94 & 0.91 & 0.86 \\
\hline 6 & 192.4 & 29.6 & 0.75 & 3 & 10.6 & 0.94 & 0.95 & 0.94 & 0.91 & 0.86 \\
\hline 7 & 219.1 & 31.3 & 0.71 & 3.98 & 9.2 & 0.9 & 0.97 & 0.91 & 0.89 & 0.8 \\
\hline 8 & 229.5 & 30.6 & 0.67 & 3.05 & 9.6 & 0.9 & 0.98 & 0.91 & 0.88 & 0.8 \\
\hline 9 & 225 & 37.5 & 0.71 & 3.88 & 11.7 & 0.97 & 1 & 0.96 & 0.94 & 0.91 \\
\hline 10 & 246.4 & 37.9 & 0.67 & 4.81 & 11.1 & 0.96 & 0.99 & 0.95 & 0.93 & 0.9 \\
\hline 11 & 236.6 & 33.8 & 0.78 & 3.5 & 11.3 & 0.97 & 0.95 & 0.96 & 0.93 & 0.91 \\
\hline 12 & 245.3 & 32.7 & 0.75 & 3 & 11.7 & 0.93 & 1 & 0.96 & 0.93 & 0.91 \\
\hline 13 & 249.6 & 41.6 & 0.75 & 5.46 & 12.2 & 0.99 & 0.99 & 0.98 & 0.97 & 0.95 \\
\hline 14 & 254.2 & 39.1 & 0.78 & 4.15 & 12.2 & 0.9 & 0.86 & 0.98 & 0.97 & 0.95 \\
\hline 15 & 275.1 & 39.3 & 0.67 & 4.5 & 13.1 & 0.99 & 1 & 0.98 & 0.97 & 0.95 \\
\hline 16 & 276 & 36.8 & 0.71 & 4.5 & 13.1 & 0.99 & 1 & 0.98 & 0.97 & 0.95 \\
\hline
\end{tabular}

1 The GRIM software was elaborated by the Department of Ocean Engineering and Marine Systems, Faculty of Maritime Technology , Szczecin University of Technology 


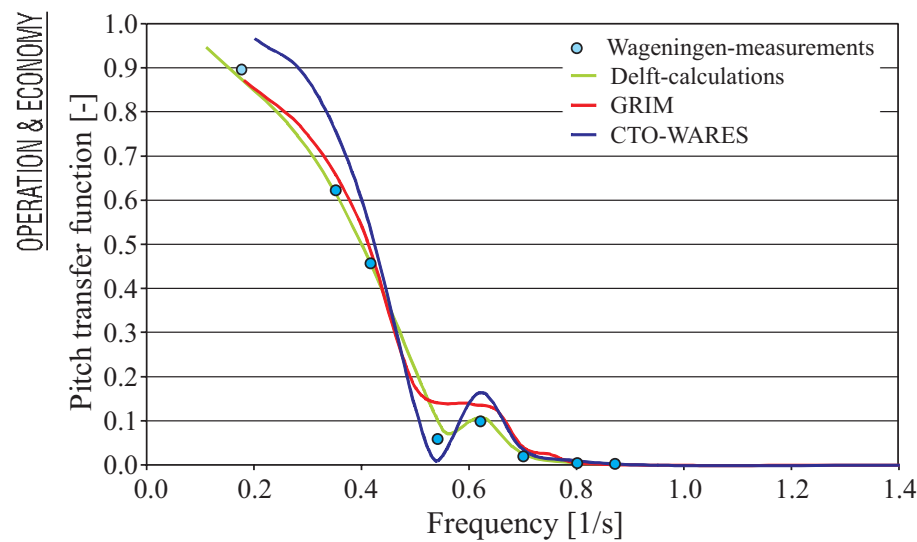

Fig. 5. Comparison of pitch transfer functions : $\boldsymbol{\beta}_{\boldsymbol{w}}=180^{\circ}$, $\boldsymbol{V}=0 \mathrm{kn} ; 200000$ dwt tanker of the length $\boldsymbol{L}=310 \mathrm{~m}$ breadth $\boldsymbol{B}=47.17 \mathrm{~m}$, draught $\boldsymbol{T}=18.9 \mathrm{~m}[3]$

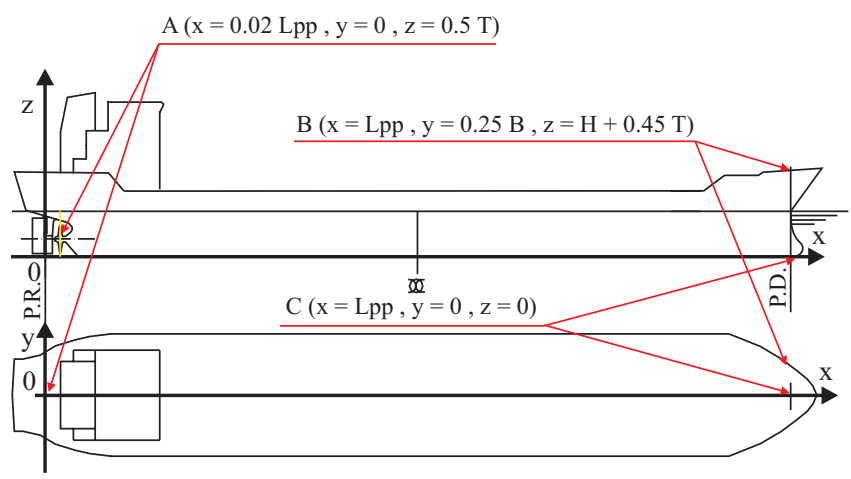

Fig. 6. Coordinates of the points at which values of the selected sea-keeping qualities were calculated: $\boldsymbol{A}$-for propeller emerging, $\boldsymbol{B}$-for green water shipping onto bow deck, $\boldsymbol{C}$-for slamming, where : $\mathbf{L p p}$ - ship length between perpendiculars, $\boldsymbol{B}$ - ship breadth, $\boldsymbol{T}$ - ship draught, $\boldsymbol{H}-$ ship depth.

\section{Test data}

The testing of approximation accuracy of the function $\mathbf{f}_{\mathbf{m}}$ was carried out on the basis of the following data :

$\rightarrow$ those contained within the range of model data (interpolation) - Tab. 2

$\rightarrow$ those from outside the range of model data (extrapolation) - Tab. 3.

The sea-keeping qualities were calculated by using the methods described in [6, 7], whereas values of the indices presented in Tab 2 and 3 - in the same way as for the model data.

Tab. 2. Test data set for interpolation :

* the ship design parameters : $\boldsymbol{L}$ - length, $\boldsymbol{B}$ - breadth, $\boldsymbol{C b}$ - block coefficient of immersed part of hull, $\boldsymbol{G M}_{\mathbf{0}}$ - initial transverse metacentric height, $\boldsymbol{T}$-draught;

* the operational effectiveness indices : $\boldsymbol{E}_{\boldsymbol{T}}$-for all sea-keeping qualities, $\boldsymbol{E}_{\boldsymbol{T}}$ roll - for rolling, $\boldsymbol{E}_{\boldsymbol{T} \text { slam }}-$ for slamming, $\boldsymbol{E}_{\text {Tprop. }}$ - for propeller emerging, $\boldsymbol{E}_{\text {Tgreen }}$ - for green water shipping onto the deck.

\begin{tabular}{|c|c|c|c|c|c|c|c|c|c|c|}
\hline Variant & $\mathbf{L}[\mathbf{m}]$ & $\mathbf{B}[\mathbf{m}]$ & $\mathbf{C b}[-]$ & $\mathbf{G M}_{\mathbf{0}}[\mathbf{m}]$ & $\mathbf{T}[\mathbf{m}]$ & $\mathbf{E}_{\mathbf{T}}$ & $\mathbf{E}_{\text {Troll }}$ & $\mathbf{E}_{\text {Tslam }}$ & $\mathbf{E}_{\text {Tprop. }}$ & $\mathbf{E}_{\text {Tgreen }}$ \\
\hline 1 & 160.75 & 26.79 & 0.78 & 2.00 & 8.93 & 0.79 & 0.88 & 0.94 & 0.91 & 0.86 \\
\hline 2 & 167.89 & 25.83 & 0.75 & 2.00 & 9.22 & 0.83 & 0.95 & 0.94 & 0.91 & 0.86 \\
\hline 3 & 191.65 & 27.38 & 0.71 & 2.00 & 8.05 & 0.79 & 0.97 & 0.91 & 0.89 & 0.8 \\
\hline 4 & 200.50 & 26.73 & 0.67 & 2.00 & 8.35 & 0.79 & 0.98 & 0.91 & 0.88 & 0.8 \\
\hline 5 & 213.52 & 35.59 & 0.71 & 3.00 & 11.12 & 0.90 & 1.00 & 0.96 & 0.94 & 0.91 \\
\hline 6 & 234.31 & 36.05 & 0.67 & 3.00 & 10.60 & 0.88 & 0.99 & 0.95 & 0.93 & 0.9 \\
\hline 7 & 224.45 & 32.06 & 0.78 & 3.00 & 10.69 & 0.88 & 0.95 & 0.96 & 0.93 & 0.91 \\
\hline 8 & 232.70 & 31.03 & 0.75 & 3.00 & 11.08 & 0.89 & 1.00 & 0.96 & 0.93 & 0.91 \\
\hline
\end{tabular}

Tab. 3. Test data set for extrapolation :

* the ship design parameters : L-length, B-breadth, $\boldsymbol{C b}$-block coefficient of immersed part of hull, $\boldsymbol{G M}_{0}$ - initial transverse metacentric height, $\boldsymbol{T}$-draught;

* the operational effectiveness indices : $\boldsymbol{E}_{\boldsymbol{T}}$-for all sea-keeping qualities, $\boldsymbol{E}_{\boldsymbol{T} \text { roll }}-$ for rolling, $\boldsymbol{E}_{\boldsymbol{T} \text { slam }}-$ for slamming, $\boldsymbol{E}_{\text {Tprop. }}$ - for propeller emerging, $\boldsymbol{E}_{\text {Tgreen }}$ - for green water shipping onto the deck.

\begin{tabular}{|c|c|c|c|c|c|c|c|c|c|c|}
\hline Variant & $\mathbf{L}[\mathbf{m}]$ & $\mathbf{B}[\mathbf{m}]$ & $\mathbf{C b}[-]$ & $\mathbf{G M}_{\mathbf{0}}[\mathbf{m}]$ & $\mathbf{T}[\mathbf{m}]$ & $\mathbf{E}_{\mathbf{T}}$ & $\mathbf{E}_{\text {Troll }}$ & $\mathbf{E}_{\text {Tslam }}$ & $\mathbf{E}_{\text {Tprop. }}$ & $\mathbf{E}_{\text {Tgreen }}$ \\
\hline 1 & 114.59 & 19.10 & 0.67 & 1.00 & 6.82 & 0.75 & 0.98 & 0.89 & 0.87 & 0.77 \\
\hline 2 & 121.31 & 18.66 & 0.71 & 1.00 & 6.22 & 0.69 & 0.89 & 0.89 & 0.85 & 0.73 \\
\hline 3 & 127.87 & 18.27 & 0.75 & 1.00 & 5.71 & 0.65 & 0.88 & 0.88 & 0.82 & 0.70 \\
\hline 4 & 134.85 & 17.98 & 0.78 & 1.00 & 5.29 & 0.65 & 0.94 & 0.87 & 0.80 & 0.67 \\
\hline 5 & 257.81 & 42.97 & 0.75 & 4.50 & 12.64 & 0.94 & 0.99 & 0.98 & 0.97 & 0.95 \\
\hline 6 & 263.04 & 40.47 & 0.78 & 4.50 & 12.65 & 0.85 & 0.86 & 0.98 & 0.97 & 0.95 \\
\hline 7 & 284.54 & 40.65 & 0.67 & 4.50 & 13.55 & 0.94 & 1.00 & 0.98 & 0.97 & 0.95 \\
\hline 8 & 285.59 & 38.08 & 0.71 & 4.50 & 13.60 & 0.94 & 1.00 & 0.98 & 0.97 & 0.95 \\
\hline
\end{tabular}

\section{Approximation}

The MLP network of 5x1x1 structure (Fig.7), characterized by the statistics described in Tab.4, appeared the best for approximating the operational effectiveness index $\mathbf{E}_{\mathbf{T}}$ for all sea-keeping qualities. 


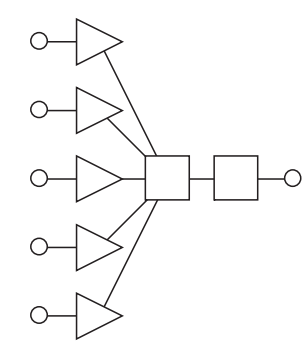

Tab. 4. Statistics of regression issues

for the neural network approximating the index $\boldsymbol{E}_{\boldsymbol{T}}$.

ig. 7. Structure of MLP artificial neural network for approximating the index $\boldsymbol{E}_{\boldsymbol{T}}$.

\begin{tabular}{|c|c|c|c|}
\hline & teaching & $\begin{array}{c}\text { testing } \\
\text { (interpolation) }\end{array}$ & $\begin{array}{c}\text { testing } \\
\text { (extrapolation) }\end{array}$ \\
\hline $\begin{array}{c}\text { Coefficient of } \\
\text { correlation R }\end{array}$ & 0.99 & 0.94 & 0.98 \\
\hline RMS error & 0.017 & 0.018 & 0.021 \\
\hline
\end{tabular}

The searched for function approximating the index $\mathbf{E}_{\mathbf{T}}$, elaborated by using the above presented neural network, is presented by means of Eq. (4), in an analytical form :

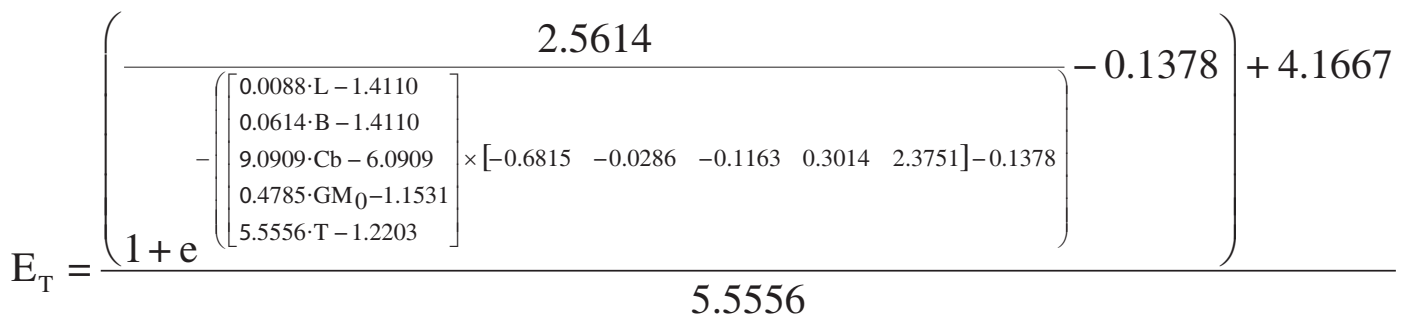

where :

L - ship length, B - ship breadth, Cb - block coefficient of immersed part of hull, $\mathrm{GM}_{0}$ - initial transverse metacentric height, $\mathrm{T}$ - ship draught.

As results from Tab. 4 and Fig. 8 and 9, the function described by Eq. (4) shows rather high accuracy both in the range of interpolation and extrapolation. Moreover, the function (4) has a very simple structure, that makes it possible to use it in the multi-criterion optimization methods based on genetic algorithms.

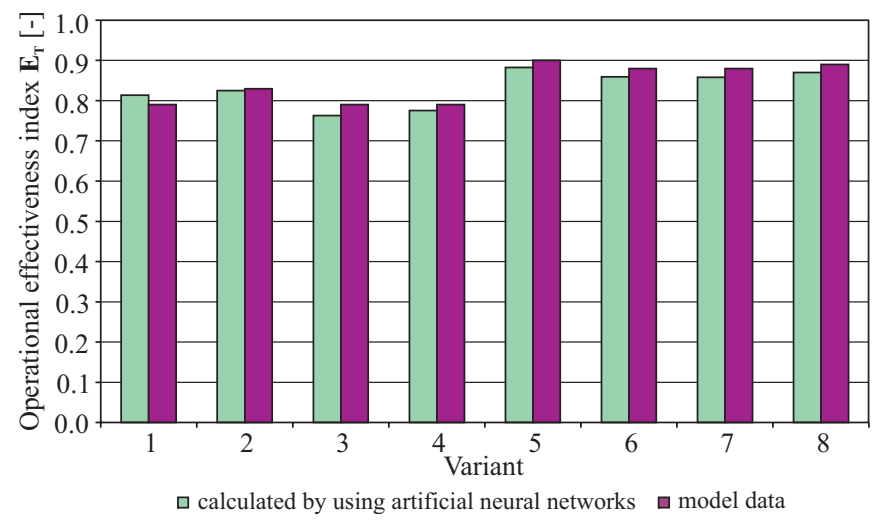

Fig. 8. Interpolation of the operational effectiveness index $\boldsymbol{E}_{\boldsymbol{T}}$ for test variants given in Tab. 2.

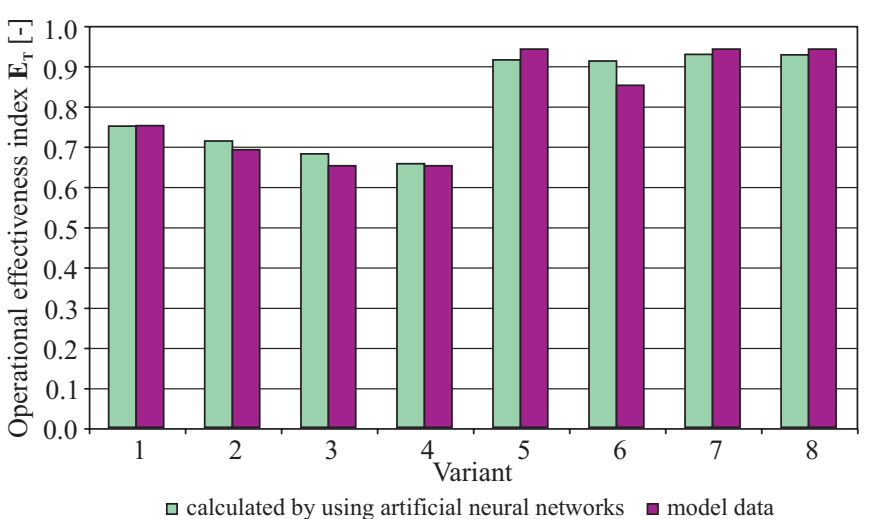

Fig. 9. Extrapolation of the operational effectiveness index $\boldsymbol{E}_{\boldsymbol{T}}$ for test variants given in Tab. 3.
In Tab. 5 are described the artificial neural networks approximating the remaining operational effectiveness indices of sea-keeping qualities such as :

$\downarrow \operatorname{rolling}\left(\mathrm{E}_{\mathrm{Troll}}\right)$

$\downarrow \operatorname{slamming}\left(\mathrm{E}_{\text {Tslam }}\right)$

$\downarrow$ green water shipping onto the deck $\left(\mathrm{E}_{\text {Tgreen }}\right)$

$\downarrow$ propeller emerging $\left(\mathrm{E}_{\text {Tprop}}\right)$.

The values of statistical parameters speak for relatively high approximation accuracy of the networks in question both in the range of interpolation and extrapolation. The neural networks are also of a relatively simple structure.

Tab. 5. Types, structure and statistical parameters of the neural networks for approximating the operational effectiveness indices : $\boldsymbol{E}_{\text {Troll }}-$ for rolling, $\boldsymbol{E}_{\text {Tslam }}-$ for slamming, $\boldsymbol{E}_{\text {Tprop. }}-$ for propeller emerging, $\boldsymbol{E}_{\text {Tgreen }}-$ for green water shipping, where: $\boldsymbol{R}$-correlation, $\boldsymbol{R M S}$ - network's error.

\begin{tabular}{|c|c|c|c|c|c|c|}
\hline \multirow[b]{2}{*}{ Parameter } & \multirow{2}{*}{$\begin{array}{r}\text { Type of } \\
\text { network }\end{array}$} & \multirow[b]{2}{*}{ Structure } & \multirow{2}{*}{$\begin{array}{l}\text { Para- } \\
\text { meter }\end{array}$} & \multirow[b]{2}{*}{ Teaching } & \multicolumn{2}{|c|}{ Testing } \\
\hline & & & & & $\begin{array}{c}\text { Inter- } \\
\text { polation }\end{array}$ & \begin{tabular}{|c|} 
Extra- \\
polation
\end{tabular} \\
\hline \multirow{2}{*}{$\mathbf{E}_{\text {Troll }}$} & \multirow{2}{*}{ MLP } & \multirow{2}{*}{$5 \times 8 \times 1$} & $\mathrm{R}$ & 0.880 & 0.850 & 0.620 \\
\hline & & & RMS & 0.015 & 0.031 & 0.035 \\
\hline \multirow{2}{*}{$\mathbf{E}_{\text {Tslam }}$} & \multirow{2}{*}{ MLP } & \multirow{2}{*}{$4 \times 2 \times 1$} & $\mathrm{R}$ & 0.990 & 0.970 & 0.990 \\
\hline & & & RMS & 0.003 & 0.016 & 0.013 \\
\hline \multirow{2}{*}{$\mathbf{E}_{\text {Tprop }}$} & \multirow{2}{*}{ MLP } & \multirow{2}{*}{$4 \times 4 \times 1$} & $\mathrm{R}$ & 0.990 & 0.950 & 0.990 \\
\hline & & & RMS & 0.005 & 0.021 & 0.019 \\
\hline \multirow{2}{*}{$\mathbf{E}_{\text {Tgreen }}$} & \multirow{2}{*}{ MLP } & \multirow{2}{*}{$4 \times 3 \times 1$} & $\mathrm{R}$ & 0.990 & 0.980 & 0.990 \\
\hline & & & RMS & 0.008 & 0.044 & 0.042 \\
\hline
\end{tabular}

\section{SUMMARY}

In this paper was presented a concept of approximation process of the operational effectiveness index by making use of basic ship design parameters. The index - according to $[1,5,8]$ - can be applied to assess ship sea-keeping performance both in the stage of ship preliminary design and in service. 
Example approximations of the index by using the artificial neural networks are also attached. The presented approximations make it possible to determine the operational effectiveness indices for the following sea-keeping qualities : rolling, green water shipping onto the deck, slamming, propeller emerging, and all the above given qualities together, on the basis of the following ship design parameters : length, breadth, design draught, block coefficient of immersed part of hull, initial transverse metacentric height.

The described approximations can be used to select a ship design which is characterized by most favourable sea-keeping qualities on a given shipping route described by statistical parameters of waves, at given criterion values for sea-keeping performance.

A way of application of the approximations may be the same as that described in [8].

The approximations make it possible to calculate the operational effectiveness index fairly accurately and in a much simpler way than in the iterative methods described in $[6,7]$.

Owing to the simple form of the functions approximating particular indices the approximations in question can be used as target functions in multi-criterion optimization methods in the preliminary ship design stage. They can be also used as a simplified method to assess a given design variant from the point of view of sea-keeping performance (without any necessity of determining ship response to wave action and taking into account occurrence probability distribution of wave parameters on a given sea area).

The presented investigation concept can be also applied to approximation of sea-keeping performance indices, carried out for :

\section{- a greater group of ships of different types \\ - various shipping routes and areas \\ - various seasons of the year.}

The approximation method in question may also find its application to the issues associated with ship operation in the phase of voyage planning. In this case ship master could be provided with useful information on sea-keeping performance of his ship on a given shipping route and in a given season, well in advance of the ship's departure, without any necessity of carrying out complex calculations.

\section{NOMECLATURE}

B $\quad-$ ship breadth

$\mathrm{Cb} \quad$ - block coefficient of immersed part of ship's hull

$\mathrm{E}_{\mathrm{T}} \quad$ - operational effectiveness index for all sea-keeping qualities

$\mathrm{E}_{\mathrm{Tslam}}$ - operational effectiveness index for slamming

$\mathrm{E}_{\text {Tprop }}$ - operational effectiveness index for propeller emerging

$\mathrm{E}_{\text {Troll }}$ - operational effectiveness index for rolling

$\mathrm{E}_{\mathrm{Tgreen}}$ - operational effectiveness index for green-water shipping

$\mathrm{GM}_{0}$ - initial transverse metacentric height

$\mathrm{H} \quad$ - ship depth

L $\quad$ - ship length

MLP - multi-layer perceptron

NSRDC - Naval Ship Research and Development Center Bethesda

$\mathrm{R}-$ - correlation coefficient

RMS - error of learning or testing the artificial neural network

$\mathrm{T} \quad-$ ship draught

$\mathrm{V} \quad-$ ship speed

$\mathrm{X}_{1}, \mathrm{X}_{2} \ldots \mathrm{X}_{\mathrm{n}}$ - ship design parameters

$\mathrm{Y}_{\mathrm{m}} \quad$ - transfer function of sea-keeping qualities

$\beta_{\mathrm{w}} \quad-$ wave heading angle relative to ship

\section{BIBLIOGRAPHY}

1. Bales N.K. : Optimizing the Sea-keeping Performance of Destroyer - Type Hulls, David W. Taylor NSRDC, Maryland, USA

2. Karppinen T. : Criteria for Sea-keeping Performance Predictions, ESPOO 1987

3. Lloyd A.R.J.M. : Seakeeping : ship behaviour in rough weather, Ellis Horwood Limited, England, 1989

4. Pinkster J.A. : Low Frequency Second-Order Wave Exciting Forces on Floating Structures, Publication No. 650, Netherlands Ship Model Basin, Wageningen - Netherlands

5. Szelangiewicz T. : Ship's Operational Effectiveness Factor as Criterion for Cargo Ship Design Estimation, Marine Technology Transaction, Polish Academy of Sciences, Branch in Gdańsk, Vol. 11, 2000

6. Szelangiewicz T., Cepowski T. : Application of artificial neural networks to investigation of ship sea-keeping ability, Part 1, Polish Maritime Research, Vol 8, no 3, 2001

7. Szelangiewicz T., Cepowski T. : Application of artificial neural networks to investigation of ship sea-keeping ability, Part 2, Polish Maritime Research, Vol 8, no 4, 2001

8. Szelangiewicz T., Cepowski T. : An approach to optimization of ship design parameters with accounting for sea-keeping ability, Polish Maritime Research, Vol.9, No 4, 2002

\section{CONTACT WITH THE AUTHOR}

Tomasz Cepowski, D.Sc.,Eng.

Institute of Marine Navigation, Maritime University of Szczecin

Wały Chrobrego $1 / 2$

70-500 Szczecin, POLAND

e-mail : cepowski@am.szczecin.pl

\section{Miscellanea Jubilee of 36-th anniversary of CTO activity}

Ship Design and Research Centre Co. (CTO S.A.) is a research, design and development institution working for Polish shipbuilding industry, which, due to its multi-year activity, has contributed in maintaining high level of novelty of ships built in Poland. Directions of research and development projects are first of all determined by needs of shipbuilding industry, that guarantees independence of technical ideas in the very important domain of national economy. Implementation of the obtained results of research projects is not limited solely to shipbuilding but also covers areas of other maritime industry and municipal economy, as well as makes it possible to export the gained knowledge and advanced technologies.

CTO takes part in activities of many international societies and organizations, initiated establishment of Polish Forum of Maritime Industries and co-operates in running Polish Technological Platform of Waterborne Transport.

$\mathrm{R} \& \mathrm{D}$ projects are realized by CTO in co-operation with many domestic economy institutions such as shipbuilding and ship-repair yards, ship equipment manufacturing firms, design offices as well as technical universities and other research centres.

Since 1998 CTO has taken part in the EU Outline Programs and realized projects both on one's own and in cooperation with foreign and domestic partners. 